\section{The impact of $\beta 2$ adrenergic receptor polymorphisms on the outcomes in cardiovascular diseases}

\author{
Ersilia Cipolletta, ${ }^{1}$ Annalisa Carillo, ${ }^{2}$ \\ Roberto Annunziata, ${ }^{2}$ Bruno Trimarco, ${ }^{2}$ \\ Antonietta Franco, ${ }^{2}$ Guido laccarino ${ }^{3,4}$ \\ 'Dipartimento di Scienze Farmaceutiche, \\ Università degli studi di Salerno; \\ 2Dipartimento di Scienze Biomediche \\ Avanzate, Università di Napoli Federico \\ II; ${ }^{3}$ Dipartimento di Medicina e Chirurgia, \\ Università degli Studi di Salerno; ${ }^{4}$ RCCS \\ Multimedica, Milano, Italy
}

\section{Abstract}

Cardiovascular diseases (CVD) include a heterogeneous group of multifactorial conditions and represent the major health problem in the western society. Many studies have evidenced that inter-individual variability affects the prognosis and the response to pharmacological treatment in patients with CVD. The identification of genetic markers to select patients more susceptible to develop cardiovascular complications has a therapeutic interest for undertaking individualized therapeutic approach. The sympathetic nervous system acts through adrenergic receptor subtypes and plays a key role in the development and prognosis of CVD. In particular, $\beta-2$ adrenergic receptors $\left(\beta_{2} \mathrm{AR}\right)$, expressed in a wide variety of tissues, are critical regulators of cardiac output, peripheral vascular resistance and metabolism. Several variations with multiple single-nucleotide polymorphisms have been identified in $\beta_{2} A R$ gene. There are 3 common $\beta_{2} \mathrm{AR}$ polymorphisms characterized in more detail for their influence on functional receptor activity. In particular, the changing an arginine for a glycine at position 16 of the receptor protein (Arg16Gly) is associated with increased agonist-induced down-regulation; the substitution of glutamine with glutamic acid at position 27 (Gln27Glu) leads to resistance to down-regulation; the substitution of threonine with isoleucine (Thr164Ile) at position 164 causes receptor uncoupling from the G protein. Many studies have indicated the association of $\beta_{2} \mathrm{AR}$ polymorphisms with various cardiovascular and metabolic diseases and have contributed to indicate the $\beta_{2} A R$ gene variants an appropriate target for investigating possible links between receptor polymorphisms, drug responses and susceptibility to CVD. However, the reports on the association of $\beta_{2} \mathrm{AR}$ polymorphisms with clinical outcomes of CVD have been contradictory. In this review, we will illustrate the effects of $\beta_{2} \mathrm{ARs}$ genetic variability on the management of CVD.

\section{Introduction}

Cardiovascular diseases (CVD) include a heterogeneous group of multifactorial conditions and represent the major health problem in the western society. ${ }^{1-3}$ Despite recent advances in the medical treatment, mortality and morbidity rates in CVD remain elevated. ${ }^{4}$ Identification of prognostic factors is an important aspect of CVD management that has been the focus of intense clinical and basic research. ${ }^{5}$ The variability of prognosis and drug responses in patients with CVD is only partially explained by factors such as medication adherence, demographic status, functional condition and behavioral attributes. ${ }^{6}$ Several studies have suggested an important role of inheritance as prognostic factors on risk and variable clinical course of CVD. ${ }^{7,8}$ Pharmacogenetic is the science that studies the role of genetic variability in determining inter-individual (between-subject) differences in the response to a pharmacologic therapy. ${ }^{9}$ In particular, the purpose of pharmacogenetic research is the use of individual genetic profiles to develop a personalized medical therapy capable to obtain an optimal drug response in subjects with a given disease. ${ }^{9}$ The sympathetic nervous system (SNS) has a wide variety of cardiovascular actions. Most of SNS functions are mediated by $\beta A R s$, G-protein-coupled receptors with a pivotal role in the regulation of cardiac output and peripheral vascular resistance. The gene encoding for the $\beta_{2} A R$ is highly polymorphic in humans and these variants may influence the sensitivity to adrenergic signal transduction. ${ }^{10}$ Moreover, $\beta_{2} A R$ gene polymorphisms are possible candidates for risk factors and predictors of response to treatment of CVD. ${ }^{11}$ In particular, Arg16Gly variant is associated with an increase of agonist-promoted down-regulation, ${ }^{1}$ while the Glu27 variant was associated with complete resistance to down-regulation. The Thr164lle polymorphism is represented within the ligand-binding pocket and its presence causes receptor uncoupling from the $\mathbf{G}$ protein ${ }^{12}$. These polymorphisms have been implicated in various cardiovascular and metabolic phenotypes ${ }^{13,14}$ To date, various case-control studies have been conducted to investigate the relationship between $\beta_{2} A R$ gene polymorphisms and cardiovascular risk in different population groups, ${ }^{1,15}$ but the results have been conflicting and inconclusive. One reason for this inconsistency may be the typically small sample size of the individual studies, which may mean that there was insufficient statistical evidence to reach an agree-
Correspondence: Guido Iaccarino, Dipartimento di Medicina e Chirurgia, Università di Salerno, via Salvador Allende, 84081, Baronissi (SA), Italy. E-mail: giaccarino@unisa.it

Key words: $\beta$ adrenergic receptor, sympathetic nervous system.

Received for publication: 4 August 2014.

Revision received: 27 November 2014.

Accepted for publication: 5 December 2014.

This work is licensed under a Creative Commons Attribution NonCommercial 3.0 License (CC BYNC 3.0).

(C) Copyright E. Cipolletta et al., 2014

Licensee PAGEPress, Italy

Cardiogenetics 2014; 4:4661

doi:10.4081/cardiogenetics.2014.4661

ment. In this review, we will illustrate the impact of $\beta_{2} \mathrm{AR}$ polymorphisms on the molecular events underlying differential responses of $\beta_{2} A R$ genetic variability on drug responses to facilitate the development of more effective therapies for the management of CVD.

\section{$\beta$ adrenergic receptors}

The $\beta$ ARs are members of G-protein-coupled receptor family ${ }^{16}$ which play a critical role in the regulation of cellular functions. ${ }^{17}$ The $\beta$ ARs share a common structure with seven hydrophobic transmembrane segments, an extracellular amino terminus and a cytoplasmic carboxy terminus that contribute to the binding pocket occupied by the ligand. ${ }^{16}$ Three different $\beta$ ARs subtypes have been pharmacologically identified and they are encoded by distinct genes. The genes are $40-50 \%$ similar and encode single polypeptide chains of between 400 and 500 amino acids. The genes encoding $\beta_{1} A R s$ and $\beta_{2} A R s$ are intronless, whereas those encoding the $\beta_{3} A R s$ have introns with part of the $\mathrm{C}$ terminus encoded by the second exon. ${ }^{18}$ Agonist-induced activation of $\beta$ ARs catalyzes the exchange of guanosine triphosphate for guanosine diphosphate on the $\mathrm{G} \alpha$-subunit of $\mathrm{G}$ proteins, resulting in the dissociation of the heterotrimer into active $\mathrm{G} \alpha$ and G $\beta \gamma$-subunits, which are competent to signal independently. ${ }^{19}$ Prolonged SNS activation induces the $\beta$ ARs desensitization, a complex of autoregulatory processes that causes a decrease of $\beta A R$ density without variation of intracellular cAMP concentration..$^{20}$ The nonagonist-specific $\beta$ AR desensitization is a rapid process in which protein kinase A phosphorylates agonist activated $\beta$ ARs at serines in the third intracellular loop and the proximal cyto- 
plasmic tail, leading to the uncoupling of the receptor from its signal-transducing $\mathrm{G}$ protein Gas. On the other hand, the agonist-specific, or homologous desensitization of $\beta$ ARs is mediated by members of the family of serine/threonine kinases termed $\mathrm{G}$ protein-coupled receptor kinases (GRKs) ${ }^{21}$ that enhances the affinity of the receptor for interaction with cytosolic proteins known as the $\beta$-arrestins. ${ }^{21}$ The binding between $\beta$-arrestin and $\beta$ AR serves to uncouple the receptor from Gs, ${ }^{21,22}$ promote internalization of desensitized $\beta A R$ s that can lead to one of several outcomes, including receptor degradation or receptor recycling back to the sarcolemmal membrane. ${ }^{22,23}$ Prolonged agonist exposure causes a net loss of cellular receptors (down-regulation) with the activation of degradation mechanisms (ubiquitination) that are independent of receptor phosphorylation. ${ }^{16}$ To restore the membrane compartment of $\beta A R$ is now required the transcription at the $\beta A R$ gene level and post-translation conversion of mRNA to protein. ${ }^{22,23}$

\section{$\beta_{2} A R$ gene polymorphisms}

The human $\beta_{2} A R$ gene, located on the long arm (q31-32) of chromosome $5,{ }^{24}$ is highly polymorphic, with over 80 polymorphisms including 49 single nucleotide polymorphism (SNP) and 4 insertion/deletion variants (Table 1). The $\beta_{2}$ AR-SNPs are organized into combinations that are inherited together into 24 haplotypes that each have a frequency of $>1 \%{ }^{24}$ Many studies have demonstrated the presence of eight SNPs within the 1.5-kb 5'untranslated region (UTR) upstream from the ATG start codon. ${ }^{24,25}$ This region contains a short open reading frame for a 19 amino acid leader peptide, called the $\beta$ upstream peptide (BUP) or the 5'-leader cistron (LC), that control the $\beta_{2} A R$ gene expression at translational level..$^{25}$ Moreover, two of the eight 5 '-UTR SNPs create and ablate restriction enzyme sites (Mspa 1 and BSu36 I, respectively ${ }^{25}$ ) and were therefore intensively investigated. Another 5'UTR SNP, which appears potentially to be important, results from a base change $(\mathrm{T} / \mathrm{C})$ at -367 bp from the start codon. ${ }^{25,26}$ It interrupts consensus AP-2 site 7 base pairs downstream of an overlapping Sp-1/AP-2 site, a region also containing strong positive promoter activity that can alter gene expression through differences in transcription factor transactivation. ${ }^{26}$ The analysis of $\beta A R s$ gene also showed that the 3'-UTR, implicated in mRNA stability and translation, contained a poly-C repeat of variable length $(11,12,13$ or very rarely $14 \mathrm{C})$, which is interrupted by polymorphisms at position 1269, giving rise to additional genetic variation.
Gly16Arg and Gln27Glu are two common $\beta_{2}$ AR SNPs in the general population and their allele frequencies vary with ethnicity. ${ }^{27}$ The Thr164Ile SNP is rare and exists only in the heterozygous state; the frequency of heterozygosity was $3-5 \%$ in all populations studied. ${ }^{28}$

There is tight linkage-disequilibrium within the $\beta_{2} A R$ gene..$^{29}$ As a result we have common haplotypes: Arg-19 is always associated with Gly16, while Cys19 is associated with either Arg16 or Gly16..$^{29,30}$ Glu27 is almost always associated with Gly16, whereas Gln27 is associated with either Arg16 or Gly16. Finally, Ile164 is closely associated with Gly16 and GIn27. Accordingly, the WT- $\beta_{2}$-AR consists of Cys19Cys-Arg16Arg-Gln27Gln-Thr164Thr. ${ }^{15,31-33}$

To characterize the functional role of $\beta_{2} \mathrm{AR}$ polymorphisms on agonist induced responses, $\beta_{2} \mathrm{AR}$ constructs expressing the SNP at position 16, 27 and 164 were assessed in specialized cell lines. ${ }^{34-36}$ In vitro studies have demonstrated that the Gly16 and Gln27 variants do not alter basal or agonist-induced ligand binding and adenylyl cyclase activity. ${ }^{35}$ However, the Arg16Gly and Gln27Glu variants affect agonist-stimulated receptor down-regulation. ${ }^{13,35}$ Gly16 genotype enhanced agonist induced downregulation of the $\beta_{2} \mathrm{AR}$ compared with the wilde type $;^{13}$ moreover, the Arg16Gly genotype has similar patterns of agonist-induced downregulation, implying that Arg16 seems to be a recessive allele. ${ }^{37}$ On the other hand, the Gln27 genotype showed attenuation of $\beta_{2} \mathrm{AR}$ agonistpromoted desensitization in comparison with those with the Gln27 genotype. ${ }^{37}$

The Gly16 variant has a dominant effect on Glu27 allele since theGly16/Glu27receptors underwent even greater agonist-promoted down-regulation than did the wild type Gln27 $\beta_{2}$ AR. $^{35}$ Conversely, the Arg16/Glu27 double mutant $\beta_{2} \mathrm{AR}$ variant was found to be completely resistant to down-regulation. ${ }^{35}$ In HLM cells both Gly16 and Glu27 polymorphism were resistant to isoprenaline-induced desensitization compared to the wild type (Arg16 and Gln27), ${ }^{38}$ however in the same cells $\beta_{2} \mathrm{AR}$ homozygous or heterozygous for Glu27 showed greater short- and long-term desensitization than those homozygous for Gln27, whereby in this population sample the presence of Glu27 was always associated with the presence of Gly16. ${ }^{35}$ In HEK 293 cells, Koryakina et al. showed that prolonged isoproterenol treatment resulted in enhanced down-regulation of Arg 16 variant due to enhanced trafficking to lysosome where the receptor is degraded. ${ }^{39}$

To investigate the role of Glu27 $\beta_{2} \mathrm{AR}$ on cardiac hypertrophy, ${ }^{13,40}$ Iaccarino et $a l^{41}$ used HEK293 lines overexpressing Glu27 and Gln27 variants of the human $\beta_{2} \mathrm{AR}$ and assessed that the Glu27 $\beta_{2} \mathrm{AR}$ variant magnifies the catecholamine induced expression of ANF promoter, a cardiac cell hypertrophy indicator. ${ }^{41}$ In COS-7 cells transfected with Arg19Cys geno- types McGraw et al. showed that Cys19 ( $\beta$ upstream peptide, also known as 5 leader cistron) allele leads to a consistently greater $\beta_{2} \mathrm{AR}$ expression as compared with the Arg19 variant, ${ }^{34}$ proposing that Arg19Cys polymorphism could represent a genetic basis for variable $\beta_{2} \mathrm{AR}$ expression, responsiveness or by this a predictive for phenotype variations. ${ }^{31,42}$ Moreover, the Gln27Glu polymorphism's association with $\beta_{2} \mathrm{AR}$ agonist-induced receptor desensitization may be explained, at least in part, by its association through linkage disequilibrium with Arg19 Cys since Gln27 is coinherited with Arg19and Glu27 is co-inherited with Cys19.34,35

Also 3'-UTR poly-C repeats polymorphisms alter $\beta_{2} \mathrm{AR}$ expression levels. Caucasians with the Arg16 genotype present three different haplotypes defined by the length of the poly-C repeats, with haplotype frequencies ranging from $14 \%$ to $43 \% .^{24}$ An in vitro study showed that cells transfected with the Arg16-11C haplotype presented lower mRNA and receptor expression, more extensive mRNA degradation and a greater tendency for $\beta_{2} \mathrm{AR}$ down-regulation as compared with the other two haplotypes. ${ }^{43}$ Such differences in Arg16 genotype may result in important phenotypic variation in the in vivo responses to $\beta_{2} \mathrm{AR}$ agonists, and may in part, explain the discrepancies in clinical studies investigating the relationship between treatment responses and Arg16-Gly polymorphism alone. ${ }^{30}$ To date, variations of the poly- $\mathrm{C}$ repeat have yet to be investigated in clinical studies, and it is highly likely that assessment of the effects of poly-C polymorphism in conjunction with other $\beta_{2} \mathrm{AR}$ polymorphisms or haplotypes would better predict therapeutic responses to $\beta_{2} \mathrm{AR}$ agonists. The effect of the Thr164Ile polymorphism on $\beta_{2} \mathrm{AR}$ binding affinity and coupling to Gs has been studied in CHW-1102 cells. In these cells, Thr164Ile polymorphism exhibited decreased receptor binding affinity with epinephrine, isoproterenol, and norepinephrine. ${ }^{44}$ Furthermore, Ile164- $\beta_{2}$ AR showed diminished reduced basal and agonist-induced activation of the adenylyl cyclase, implying a diminished $\beta_{2}$ AR-G protein interaction. ${ }^{35}$

The impact of the $\beta_{2} \mathrm{AR}$ 16Gly and Glu27 variants on agonist-induced desensitization, have been investigated in studies in vivo, and data were quite controversial. ${ }^{28}$ Some studies have evaluated the effect of the Gly16Arg $\beta_{2} \mathrm{AR}$ on the cardiovascular response to exercise showing that homozygote Gly16 $\beta_{2} \mathrm{AR}$ subjects have an increased cardiac stroke volume and cardiac output both at rest and during exercise compared with homozygote $\beta_{2} \mathrm{AR}$ Arg16.,45,46 On the other hand, in healthy subjects, other reports have found that the increase of heart rate, contractility and blood pressure (BP) such as are not significantly affected by the Arg16 and Gln27 variants genotypes. ${ }^{31,47-49}$ 
Other investigations have demonstrated that isoprenaline induced increases in forearm blood flow or dilation of hand vein and found that volunteers homozygous Gly16 exhibited larger vasodilatory responses than did volunteers homozygous Arg16.48,50

Because the Glu27 variant of $\beta_{2} \mathrm{AR}$ causes resistance to down-regulation and therefore attenuation of agonist promoted functional desensitization. $^{40,51}$ It can be considered a gain-of-function mutation because of the longer duration of stimulation. Indeed, subjects who are homozygous for Glu27 have a significantly higher maximal forearm vasodilation to intra-arterial isoproterenol than those who are homozygous for Gln27, regardless of the amino acid present at position $16 .^{48}$ It is therefore conceivable to speculate that cardiac Glu27 $\beta_{2} \mathrm{AR}$ drives an exaggerated hypertrophic response to catecholamines. ${ }^{48}$ Some other reports in the literature contradict these findings, showing that other $\beta_{2}$ AR-dependent physiologic responses are depressed in the presence of the Glu27 polymorphism in vivo. Interestingly, Bruck et al. found that volunteers homozygous for Glu27 $\beta_{2}$ AR exhibited a slowed onset in desensitization of cardiac responses or in down-regulation of lymphocyte $\beta_{2} A R$ density, and this occurred although volunteers carried two or one allele Gly16. ${ }^{49,51}$ There is not a consensus on the reasons for the discrepancies between in vitro and in vivo. One possible explanation is the antagonizing effect on desensitization of the Gly16 polymorphism, which is in linkage disequilibrium with Glu27, although this viewpoint is also challenged by recent evidence showing that the Gly16 allele may lead to enhanced physiologic responses in vivo. ${ }^{12}$

The Thr164Ile variant of the $\beta_{2} \mathrm{AR}$ occurs only rarely and is found only in the heterozygous form, ${ }^{37}$ the majority of subjects carrying the Thr164Ile polymorphisms are also carriers of Gly16 variant in combination with the Gln27 variant. ${ }^{29,51}$

Thr164lle variant does alter ligand binding and $\mathrm{G}$ protein coupling. In cells transfected with cDNA that mimics this SNP, the Ile164 receptor displays a lower binding affinity for $\beta_{2} \mathrm{AR}$ agonists, a $50 \%$ reduction in agonistinduced adenylyl cyclase activity, and uncoupling of the receptor from the $\mathbf{G}$ protein compared with the wild-type receptor. ${ }^{36,44}$ In transgenic mice the expression of Ile164 receptor in myocardium tissue impairs resting heart rates and inotropic and lusitropic indices. ${ }^{52}$ The Ile164 variant of the $\beta_{2} A R$ gene in endothelial cells loses the ability to mediate cell specific responses to catecholamine..$^{53,54}$ To gain better insight on the role of Ile164 on atherosclerosis, Piscione et al. showed that adenoviral (Ad) $\beta_{2} \mathrm{AR}$-Ile164 infection reduces isoproterenol mediated Vascular smooth muscle cells (VSMC) proliferation. ${ }^{55}$ In humans, vascular responses and heart contractility are altered in subjects carrying the Ile164 variant of the $\beta_{2} A R$ gene compared with wild-type volunteers. $^{32,54,56,57}$

The analysis of effects of $\beta_{2} \mathrm{AR}$ polymorphisms is therefore inevitably complicated by the strong Linkage Disequilibrium among SNPs which results in the occurrence of several common haplotypes resulting in multilocus effects. ${ }^{29}$ These limitations make most unlikely that genetic-epidemiological data alone give details in relevant functional alterations of polymorphic $\beta_{2} \mathrm{AR} .^{15,28,32}$ Taken together, the available data demonstrate that the $\beta_{2} \mathrm{AR}$ polymorphism might affect functional responsiveness in vitro, ex vivo and in vivo and appear to be associated with cardiovascular disease states in which $\beta_{2} A R$ are considered to be important.

\section{$\beta_{2} A R$ gene polymorphisms in hypertension}

Hypertension is a multifactorial condition that represents the most important risk factor for cerebral ictus, myocardial infarction and heart failure (HF), as well as the one with the highest incidence in the population, peaking at $60-70 \%$ at advanced age. Several studies have identified genetic factors that influence $\mathrm{BP}$ and metabolic responses to $\beta$-blockers, thiazide diuretics, and rennin-angiotensin system antagonists. Whether such pharmacogenetic differences translate to differences in the clinical outcome of antihypertensive therapy is less clear, particularly when patients receive multiple drugs that are titrated to a target BP. ${ }^{3}$ A pharmacogenetic approach to treating hypertension could not only reduce the number and cost of medications but also reduce morbidity and mortality if the outcome of drug treatment differs by genotype. Given the pivotal role of $\beta_{2} \mathrm{ARs}$ in the regulation of cardiac output and peripheral vascular resistance, several studies proposed $\beta_{2} \mathrm{AR}$ gene polymorphisms as strong candidates for risk factors and predictors of response to treatment of hypertension. $1,58,59$ The association between hypertension and Gly16 variant was found in Africans, ${ }^{11}$ but no association either for Arg16 or Gly16 with hypertension was confirmed in a Japanese population $^{60}$ or black and white Americans. ${ }^{61}$ Another study investigated sib-pairs from 55 pedigrees and about 2500 additional subjects from 589 families, found that the risk for hypertension was greater for those subjects carrying the Gly16 and Glu27 alleles. ${ }^{62}$ A metaanalysis conducted on eleven previous studies indicated that $\beta_{2} \mathrm{AR} 16 \mathrm{Arg}$ polymorphism was associated with hypertension susceptibility in Han Chinese population. ${ }^{63}$ Recently Kumar et al. evaluated the role of genotypes on aug- mented hypertension susceptibility and observed that $\beta_{2} \mathrm{AR} 16 \mathrm{Arg}$ variant represents a risk-conferring marker of hypertension, associated with decreased $\beta_{2} \mathrm{AR}$ expression in the 546 hypertensive patients. ${ }^{64}$ There is a close relationship between hypertension and renal function, ${ }^{65}$ but the pathogenesis of arterial hypertension in renal disease is complex and not completely understood. Genes of vascular homeostasis play an important role in development and progression of chronic glomerulonephritis (CGN) an immune-mediated glomerular disease, which often associated with hypertension, and may result in renal failure and respective increased mortality ${ }^{66}$ In recent study of Litovkina et al. observed that $\beta_{2} \mathrm{AR} 16$ Arg variant is associated to development of hypertension and accelerated decline in kidney function in Russian patients suffering from CGN. ${ }^{67}$

The $\beta$-blockade treatment induces a vascular remodeling that correlates with changes in left ventricular wall thickness in hypertensive patients. $^{68}$ Based on these observations Iaccarino et al. $^{40}$ assessed the impact of the $\beta_{2} \mathrm{AR}$ polymorphisms on cardiac and vascular target organ damage in a population of untreated essential hypertensive patients after evaluation of clinical, anamnestic and biochemical data. This study showed that $\beta_{2} A R$ gene polymorphisms had no effect of BP values, but affects cardiac remodeling in response to hypertension. In particular, the presence of Glu27 variant is associated to a significantly higher risk of cardiac hypertrophy compared to patients with the Gln27 allele. The effects of Glu27 polymorphism are more predominant in younger patients while it seems to fade with age. The effect of the presence of Glu27 polymorphism on the cardiac remodeling might be related to the gain-of-function in signal transduction induced by the mutation on $\beta_{2} A R$ gene. ${ }^{37}$ In a subsequent study laccarino et al. ${ }^{41}$ investigated the effects of $\beta_{2}$ AR variants on the left ventricular mass index (LVMi) regression when BP is reduced with $\beta_{1}$-blockers (Atenolol), which are unable to completely block $\beta_{2} \mathrm{AR},{ }^{69,70}$ rather than with angiotensin-converting enzyme (ACE) inhibitors (Enalapril), which in hypertension reduce the whole sympathetic discharge. ${ }^{71-73}$ This study showed that Glu27 patients presented a higher reduction in LVMi than Gln27 patients independently from treatment. ${ }^{41}$ Moreover, the patients harboring Glu27 $\beta_{2} \mathrm{AR}$ showed a larger regression of LVMi when treated with enalapril rather than atenolol. These results have supported suggested that in Glu27 patients an important effect of antihypertensive therapy on regression of left ventricular hypertrophy (LVH) is mediated through a nonBP-dependent mechanism, but depends on enhanced hypertrophic effect of the sympathetic system. ${ }^{41}$ ACE inhibitors, which reduce the sympathetic discharge overall, ${ }^{73}$ are also able to 
reverse LVH through the reduction of the hypertrophic effect of catecholamines. ${ }^{74}$ This property may be particularly relevant in Glu27 patients, because by reducing sympathetic activation, it may prevent the more marked catecholaminemediated hypertrophy stimulus induced by the Glu27 $\beta_{2}$ AR variant.

Few studies have investigated the effect of Thr164lle on hypertension. Pereira et al. reported increased systolic BP in Thr164Ile heterozygotes compared to non carriers in a ethnically mixed Brazilian population. ${ }^{75}$ Furthermore, no significant association between Thr164Ile genotype and hypertension was found in a linkage study with 638 participants from 212 Polish pedigrees with clustering of hypertension. ${ }^{76}$ The lack of consistency amongst these studies may be attributable to ethnic differences in study subjects. Another explanation could be that analyses were not stratified by gender in any of these previous studies, probably due to the loss of power resulting from the reduction in sample size. Thr164Ile heterozygosity was associated with increased diastolic BP in women, but not in men in the Copenhagen City Heart Study. ${ }^{77}$

\section{$\beta_{2} A R$ polymorphisms in coronary artery disease}

Coronary artery disease (CAD) is one of the leading causes of death in the world, despite the improvement of diagnostic and therapeutic tools. Elevated levels of catecholamines lead to increased $\beta A R$ activity that results in progressive coronary atherosclerosis and deterioration of cardiac functions. ${ }^{78} \beta_{2}$ ARs play a pivotal role in the control of myocardial contractility of the failing heart ${ }^{79}$ and several studies have proposed that $\beta_{2} \mathrm{AR}$ polymorphisms may be important determinant of CAD. However, the impact of $\beta_{2} \mathrm{AR}$ polymorphisms on coronary atherosclerosis and cardiovascular clinical events is highly controversial. In the study of Yamada et al., none of the $\beta_{2} \mathrm{AR}$ polymorphisms was associated with increased risk form of myocardial infarction in a Japanese population. ${ }^{80}$ On the other hand, a large series of studies support the association with atherosclerosis. In an observational cohort study in the elderly the Glu27 allele of the $\beta_{2} \mathrm{AR}$ was associated with a lower risk of incident coronary events in this elderly population. ${ }^{81}$ Analysis of the patient cohort from the Physicians' Health Study demonstrated that only specific haplotype combinations ([nonGly16-Gln27]-Thr164 and Gly16-Gln27-Ile164) increased the risk for myocardial infarction but this association disappeared after adjustment for other polymorphisms. ${ }^{82}$ Furthermore, Barbato et al. demonstrated that that prevalence of Glu27 variant is higher among CAD patients in central European population and the presence of this allele should be considered an independent disease risk factor for coronary artery disease ${ }^{83}$ Zak et al. observed a significantly higher prevalence of the Arg allele of Arg16 Gly polymorphism in coronary artery disease (CAD) patients than healthy controls. ${ }^{76} \mathrm{~A}$ significant correlation between 27Glu allele carrier state and CAD was noted in patient population in Saudi Arabia. ${ }^{84}$ Although the rare incidence, individuals with the Ile164 allele and normal LV function show blunted hemodynamic responses to adrenergic stimulation..$^{28}$ Barbato et al. showed that Thr164Ile polymorphism negatively modulates $\beta_{2}$-agonist-mediated myocardial contractile performance in patients with normal and failing myocardium and this $\beta_{2} \mathrm{AR}$ variant is associated with adverse long-term prognosis of patients with congestive HF due to idiopathic cardiomyopathy. ${ }^{56}$ Moreover, Piscione et al. found a relationship between $\beta_{2}$ AR Ile164 polymorphism and coronary and peripheral artery disease in a prospective study in which were enrolled 330 patients undergoing elective or urgent percutaneous coronary intervention (PCI) for CAD documented. ${ }^{55}$ Interestingly, this study evidenced that Ile164 polymorphism frequency was higher in $\mathrm{CAD}(12.1 \%$ vs $3 \%$, $\mathrm{P}>0.008$ ) than the control population; $\beta_{2} \mathrm{AR}$ Ile164 mutant is associated with an earlier and more aggressive $\mathrm{CAD}$, and it adversely affects prognosis in patients with severe CAD undergoing PCI. This evidence also showed that a group of patients with peripheral artery disease exhibited a higher prevalence of the Ile164 genotype (7\%) with a more severe clinical phenotype than those with Thr164. ${ }^{55}$ These data support the concept that $\beta_{2} \mathrm{AR}$ polymorphism may predict prognosis in CAD.

Nevertheless studies that address the association of $\beta_{2} \mathrm{AR}$ polymorphisms and outcomes in patients with ischemic heart disease present conflicting results. First of all, McLean showed that specific genetic variations present in the $\beta_{2} A R$ genes would predict LV remodeling in patients chronically treated with a $\beta_{1}$ selective antagonist following a first ST elevation myocardial infarction (STEMI) ${ }^{85}$ Specifically, the Glu27Glu variant was associated with an approximately seven-fold increased risk of LV end systolic dilatation, and a fourfold risk of end diastolic volume enlargement and LV ejection fraction decline at 6 months when compared to the full cohort. ${ }^{85}$

Coronary artery spasm (CAS) is also associated to a wide spectrum of ischemic heart diseases, ranging from variant angina pectoris to acute myocardial infarction and even sudden cardiac death.$^{86}$ Given the important role of the SNS in CAS pathophysiology, some studies have evaluated whether genetic polymorphisms affecting autonomic activity contribute to the pathogenesis of CAS. ${ }^{87}$ Among the numerous polymorphisms related to the SNS, Park et al. have found that $\beta_{2} \mathrm{AR}$ Gln27 allele homozygote state were associated with CAS in a Korean population. ${ }^{88}$ On the other hand, Zhou et al. failed to confirm these data in Chinese population. ${ }^{89}$

\section{$\beta_{2} A R$ gene polymorphisms and heart failure}

One complication of myocardial infarction is the development of adverse left ventricular remodeling and progression to HF. Increased cardiac adrenergic activity is one of the major determinants of the progression of LV dysfunction and the poor outcomes of the patients with HF. Acute and long-term therapy with $\beta$ blockers has become a standard following acute myocardial infarction and HF. Therapy with $\beta$-blockers reduce infarct size and mortality among myocardial infarction and $\mathrm{HF}$ patients, most likely by decreasing cardiac energy requirements and modifying arrhythmic risk. Some studies suggested that genetic polymorphisms may mediate differential therapeutic end points of $\beta$-blocker treatment, including left ventricular ejection fraction improvement, survival, and hospitalization due to HF exacerbation. However, the association of genetic $\beta_{2} \mathrm{AR}$ polymorphisms and therapeutic end points of $\beta$-blocker treatment is objected of controversy. Pacanowski et al. investigated the influence of $\beta_{1} A R$ and $\beta_{2} A R$ haplotype variation on the incidence of death, nonfatal myocardial infarction, and nonfatal stroke as well as the pharmacogenetics of $\beta$-blocker (atenolol) and calcium channel blocker (verapamil) based antihypertensive therapy in the INternational VErapamil SR/Trandolapril Study

GENEtic Substudy (INVEST-GENES). ${ }^{90}$ Authors showed that patients with the $\beta_{2} \mathrm{AR}$ haplotype containing the Arg16 and Gln27 alleles would be at relatively higher risk for cardiovascular events and that atenolol would be beneficial as compared with sustained-release verapamil (verapamil SR). Pharmacogenetic analysis revealed that the risk for the primary outcome was significantly higher in Glyl6Glu27 haplotype in verapamil SR-treated patients but not in atenolol-treated patients. The analysis revealed that patients with at least one copy of the Ser49-Arg389 $\beta_{1}$ AR haplotype and zero copies of the Gly16-Glu27 $\beta_{2} \mathrm{AR}$ haplotype (representing $42 \%$ of the study population) had better outcomes when treated with atenolol than with verapamil SR (HR 0.42, 95\% CI 0.21-0.82, $\mathrm{P}=0.01$ ). Comparing this result to the HR of 0.64 when considering the $\beta_{1} A R$ gene alone suggests that a consideration of both genes may be even more informative for identifying those most likely to benefit from $\beta$-blocker therapy. ${ }^{90}$ In another study per- 
formed on $80 \mathrm{HF}$ patients treated with the nonselective $\beta$-blocker carvedilol, Kaye et al. demonstrated that subjects carriers of the Glu27 allele were more likely to have an increase in ejection fraction or fractional shortening than those who were homozygous for the allele encoding the Gln27 variant (63 vs $26 \%, \mathrm{P}=0.003$ ) thus suggesting that determination of $\beta_{2} \mathrm{AR}$ status may be of value for tailoring individual therapy in patients with $\mathrm{HF}^{91}$ In contrast, De Groote observed that $\beta_{2} \mathrm{AR}$ polymorphisms did not explain the interindividual variability in the response to $\beta$-blocker therapy. ${ }^{92}$ In a recently published study, a $\beta_{2}$ AR haplotype (Arg16Arg26/Gln27Gln) was associated with increased risk for death or heart transplantation in 220 patients, 95 (80\%) of whom were on an ACE inhibitor/angiotensin receptor blocker and a $\beta$-blocker at baseline. ${ }^{93}$ When considered relative to $\beta$-blocker use, this association was most strongly driven by those not on a $\beta$-blocker (HR of 3.52 vs HR of 1.55). These results suggest that certain genotypes/haplotypes may be at increased risk of adverse outcomes and that $\beta$-blockers may attenuate the risk associated with that genotype/haplotype. Interestingly, these findings are consistent with those from an acute coronary syndrome population, in which the Arg16Gln27 haplotype was also associated with adverse outcomes, even among those treated with a $\beta$-blocker. ${ }^{94}$ Collectively, these data may suggest that the Arg16GIn27 haplotype of the $\beta_{2} \mathrm{AR}$ may be a high-risk haplotype group deserving of more aggressive therapy. Confirm to this view derives from Troncoso et al., who have evaluated the influence of Gln27Glu $\beta_{2} \mathrm{AR}$ polymorphism on the variable response to treatment with carvedilol in patients with chronic HF. ${ }^{95}$ The results of this study showed that chronic HF patients with the Glu27 $\beta_{2} \mathrm{AR}$ allele have a better response to carvedilol..$^{95}$

For the more clinically relevant outcome of survival in HF patients, the results are mixed. Brodde et al. observed that HF patients with the Arg16Arg-Gln27Gln- $\beta_{2}$ AR seem to have a more pronounced adverse outcome (heart transplantation) and increased risk for sudden cardiac death. ${ }^{28}$ In a prospective study on large cohort of clinically treated HF patients who had been prescribed metoprolol or carvedilol Sehnert et al. failed to found significant effect of $\beta_{2} \mathrm{AR}$ genotypes on incidence of critical end point of survival in $\beta$-blocker-treated $\mathrm{HF}$ patients. ${ }^{96}$ Similar results were obtained by de Groote $e t$ al. that found no association between functional $\beta$ AR polymorphisms and survival in patients with stable HF. ${ }^{97}$ However, the authors demonstrated, with a univariate analysis, a possible association between the combined $\beta_{2}$ ARGly16Gly $/ \beta_{2}$ ARGln27Gln genotype and survival. ${ }^{97}$ Recently Petersen et al. showed that $\beta_{1}$ AR Arg389-homozygous and $\beta_{2}$ AR Gln27-carrier HF patients treated with carvedilol present a two-fold major risk of mortality relative to all other genotype combinations. ${ }^{98}$ There was no difference in survival in metoprolol-treated HF patients between genotype groups. ${ }^{98}$ The data indicate that patients with $\beta_{1} \mathrm{AR}$ and $\beta_{2} \mathrm{AR}$ genotypes may benefit more from metoprolol than carvedilol treatment.

In HF, the Thr164lle polymorphism is characterized by reduced exercise tolerance and higher mortality ${ }^{48}$ However, pathophysiological mechanisms contributing to the poor outcome of these patients are not clear and it is unclear whether the poor outcome is related to direct effects of the Ile164 polymorphism on the myocardial contractile performance or to systemic hemodynamics. Preliminary study showed that in chronic HF-patients, terbutaline-induced increases in heart rate, but not in contractility, were not different in patients with the Thr164Thr or the Thr164lle variant of the $\beta_{2} \mathrm{AR}^{56,57,83}$ On the other hand, Wagoner et $a l$. assessed in chronic HF-patients either heterozygous Thr164Ile or homozygous Thr164Thr exercise capacity and found that patients with the Thr164Ile variant of the $\beta_{2} \mathrm{AR}$ 8 had a lower peak V 02 than patients homozygous Thr164Thr. ${ }^{99}$ Moreover, Liggett et al. ${ }^{37}$ genotyped 259 patients with $\mathrm{HF}$ due to ischemic or dilated cardiomyopathy and found that the allele frequencies for the Arg16Gly, Gln27Glu and Thr164Ile polymorphisms of the $\beta_{2} \mathrm{AR}$ did not differ with those assessed in 212 healthy controls. However, those patients carrying the Thr164lle polymorphism had much more rapid progression to transplantation or death ${ }^{37}$ these data is challenged by the observation from Leineweber in 2006, showing that the frequency of the Ile164 allele is almost identical in healthy controls, chronic HFpatients and heart transplantation-patients. ${ }^{100}$

Several factors contribute to ventricular tachyarrhythmias and sudden cardiac death (SCD) in HF patients and most of them are still completely understood. In this setting, the modulation of $\beta A R$ activity with pharmacological treatment plays a protective role against cardiac arrhythmias. ${ }^{33}$ Given their properties to modulate $\beta$-ARs activity and $\beta$-blockers efficacy, $\beta A R$ gene polymorphisms might contribute in the risk stratification for ventricular tachyarrhythmias and appropriate implantable cardioverter defibrillatorr (ICD) shocks. ${ }^{101}$

It has been observed that Gln27 homozygous patients have an increased risk of $\mathrm{SCD}^{102}$ and that the Arg16Gln27 haplotype may significantly increase the risk of adverse outcomes in HF patients..$^{93}$ Recently, Pezzali et al. have indicated for the first time that $\beta_{2} \mathrm{AR}$ polymorphisms affect reverse remodeling and arrhythmic events after cardiac resynchronization therapy (CRT) in patients with $\mathrm{HF}^{101}$. This study shows that carriers of the Glu27Glu $\beta_{2} \mathrm{AR}$ variant is associated to greater improvement in LVEF after CRT compared with GIn27 homozygous patients. In addition, Gln27 homozygotes which had a higher incidence of arrhythmic events presented an increased rate of appropriate ICD shocks and cardiac events compared with the other patients. ${ }^{101}$

\section{$\beta_{2} A R$ polymorphisms and stroke}

Stroke is the second most common cause of death and disability worldwide. It is a multifactorial disease influenced by both environmental and genetic factors. The age-related decline in $\beta A R$ receptor function and subsequent cyclic AMP generation ${ }^{103}$ is a common factor underlying atherosclerosis, vascular insufficiency and hypertension. ${ }^{104}$ Stroke is a multifactorial, polygenic disorder, influenced by both environmental and genetic factors. There are several risk factors has been discovered for stroke, such as hypertension, diabetes, smoking, dyslipidemia etc., however these risk factors do not explain why some individual are more susceptible to these environmental determinants in comparison to others with same given risk factors. ${ }^{105}$ Some studies have shown that age-associated decline in $\beta$-adrenergic receptor sensitivity in the cardiovascular system. ${ }^{106} \mathrm{~A}$ growing body of evidence, suggesting that genetic variant may predispose to developing stroke. ${ }^{107}$ Few studies have addressed the association of $\beta_{2} \mathrm{AR}$ polymorphism with ischemic stroke and both positive and negative associations have been reported. A case control study, reported from Italy, indicated a positive association between Gln27Glu polymorphism and ischemic stroke. ${ }^{108} \mathrm{~A}$ previous study by Heckbert et al., failed to show significant association of $\beta_{2} \mathrm{AR}$ variant with the incidence of stroke. ${ }^{81} \mathrm{~A}$ prospective cohort study included 25,225 women showed that the different haplotypic combination of $\beta_{2} A R$ gene variant did not affect the incidence of ischemic stroke in women. ${ }^{109}$ A case control study reported by Zhao et al. did not find significant association of Gln27Glu polymorphism with risk of ischemic stroke, however, higher frequency of variant Glu27 allele in ischemic stroke patients than controls has been observed. ${ }^{110} \mathrm{~A}$ recent case control study confirmed the relationship between $\beta_{2} \mathrm{AR}$ Glu27Glu polymorphism and ischemic stroke in North Indian subjects, ${ }^{111}$ suggesting that that Glu27Glu polymorphism may confer higher risk of large vessel disease stroke in this population. ${ }^{112}$ These preliminary evidences allow to hypothesize that the identification of a subgroup of patients, who are carrier of $\beta_{2} \mathrm{AR}$ receptor polymorphism, may have implication for planning their future stroke treatment strategies. 


\section{Role of $\beta_{2} A R$ polymorphisms in metabolic disturbances}

The adrenergic system controls glucose and lipid metabolism in the liver, adipose tissue, and skeletal muscle, in part through the $\beta_{2} \mathrm{AR}$. The catecholamines stimulate hepatic glucose production to some extent through the $\beta_{2} \mathrm{AR}$, and also regulates pancreatic insulin secretion. ${ }^{113}$ Therefore, the $\beta_{2}$ AR may also constitute a potential candidate gene to explain part of the genetic predisposition to dyslipidemia and related traits. Several investigations have identified associations between $\beta_{2} \mathrm{AR}$ polymorphisms and metabolic disorders such as hypertriglyceridemia, insulin resistance, and obesity. ${ }^{114-117}$ Landsberg ${ }^{118}$ and Julius ${ }^{119}$ have proposed that hyperinsulinemia and insulin resistance stimulate sympathetic nervous activity and thermogenesis to limit further weight gain in obese subjects. ${ }^{120}$ On the other hand, some longitudinal studies observed that sustained sympathetic activity was the prime mover for future weight gain in originally non-obese, normotensive subjects, and that insulin resistance was more an accessory factor. ${ }^{121,122}$ The $\beta_{2} \mathrm{AR}$ is the dominant lipolytic receptor in adipose tissue ${ }^{123,124}$ and in skeletal muscle. ${ }^{125}$ The $\beta_{2} \mathrm{AR}$ activation increases the intracellular cyclic AMP levels that activate protein kinase A, which in turn promotes activation of hormone-sensitive lipase that catalyses the ratelimiting step in lipolysis. ${ }^{126,127}$ Recent evidences indicate that a genetic component is important in the pathogenesis of obesity-related hypertension and insulin resistance. ${ }^{128}$ In particular, has aroused great interest the observation that $\beta_{2} \mathrm{AR}$ polymorphisms cause marked variations in catecholamine-induced lipolysis in fat cells. ${ }^{129}$ Some investigation have observed a strong evidence for the linkage between $\beta_{2} \mathrm{AR}$ polymorphisms, heightened sympathetic nervous system activity, obesity, hypertension, and the development of insulin resistance. ${ }^{115}$ Current studies allow the speculation that the Glu27 variant might be associated with higher indices of obesity, higher body fat, larger fat cell volume and higher fasting insulin levels when compared with the Gln27 allele. ${ }^{31,124}$ However, although the Glu27variant has been associated with obesity ${ }^{124,130}$ and Type II diabetes, ${ }^{131}$ the findings have not been replicated in all studies. ${ }^{132,133}$

Masuo et al. ${ }^{128}$ observed that originally nonobese, normotensive subjects carrying the Gly16 allele is associated to high plasma norepinephrine levels and to increase of weight gain and BP. In a weight loss study, the $\beta_{2} \mathrm{AR}$ the Gly16 allele of Arg16Gly was associated with resistance to long term significant weight loss, and the Glu27 allele was linked to resistance to short-term weight loss moreover, lean normotensive men carrying the Gly16 allele of
Arg16Gly had a higher frequency of insulin resistance. $^{134}$ Ishiyama-Shigemoto et al. assessed the role Gln27Glu substitution in the development of obesity and obesity-related metabolic disorders and observed that Gln27Glu substitution was higher in obese subjects and in patients with Type II (noninsulin-dependent) diabetes mellitus than control subjects. ${ }^{135}$ Moreover, this study indicated that the obese subjects carrying the Gln27Glu variant allele had higher concentrations of serum triglyceride than obese subjects homozygous for the wild type allele. ${ }^{135}$ Conversely, the frequency of Gly16 homozygotes was lower in obese women when compared with non-obese women, although the association was not present in male subjects. ${ }^{124}$ These results were not confirmed by another study on general population of northern France, in which the Gln27Glu variant did not significantly influence body mass index (BMI). ${ }^{136}$ The phenotypic effect of two common $\beta_{2} \mathrm{AR}$ polymorphisms on body weight and/or plasma lipid and lipoprotein abnormalities were also examined by Ehrenborg et al. in a homogeneous and representative population of Swedish healthy men. ${ }^{137}$ This study observed BMI, such as VLDL cholesterol and triglyceride concentrations were significantly increased in individuals carrying the Gln27Glu variant. ${ }^{137}$ Iaccarino et al. tested the hypothesis that in hypertensive patients a given polymorphism of $\beta_{2}$ ARs might predict the occurrence of metabolic adverse events during $\beta A R$ blocking treatment. ${ }^{14}$ In particular, in this study were evaluated the effects of $\beta_{2} \mathrm{AR}$ polymorphism in hypertensive population, which are involved in glucose and lipid metabolism, on the occurrence of diabetes and dyslipidemia observed after long-term treatment with $\beta$-blockers. The $\beta_{2} \mathrm{AR}$ Glu27 variant resulted associated with a larger occurrence of dyslipidemia due to increased serum triglycerides, independently from treatment. ${ }^{14}$ Treatment with $\beta$-blockers in these patients associates with a further significant increase of elevated serum triglycerids and combined dyslipidemia. On the contrary, $\beta$-blockade in patients harboring this polymorphism did not change the occurrence of diabetes or low HDL. This result is particularly noteworthy, because it allows to identify a subpopulation where the occurrence of dyslipidemia after $\beta$-blockade is very likely, with an incidence that is above $60 \%$. The identification of this subpopulation makes safer the longterm treatment with $\beta$-blockers in patients who do not carry the polymorphism and who represent the majority of hypertensive patients. ${ }^{14}$ Another study observed that metoprolol succinate or carvedilol treatments were associated with a significant increase of baseline insulin and triglycerides levels in hypertensive patients with the Glu27Glu and Gly16Gly genotypes compared with the
Gln27Gln and Arg16Arg genotypes; moreover the magnitude of triglycerides elevation over time following $\beta$-blocker treatment was significantly higher among the subjects with the Arg16Arg genotypes, despite lower initial concentrations. $^{138}$ These data are in line with those of Iwamoto et al. ${ }^{117}$ who described the same association between the $\beta_{2} \mathrm{AR}$ Glu27 variant and hypertriglyceridemia in unselected populations. According with these data, Daghestani et al. ${ }^{139}$ observed that in overweight and obese subjects, while did not differ in the genotype and allele frequencies of Glu27, the subjects Glu27 homozygote have greater BMI, waist and hip circumference, higher triglyceride, insulin and leptin levels. ${ }^{139}$ Similarly in another study Kunnas et al., observed significantly higher amount of visceral fat in women with Glu allele compared to Gln/Gln homozygote. ${ }^{140}$ Ishiyama et al., have suggested an association of polymorphisms in the $\beta 2 A R$ receptor gene with obesity, hypertriglyceridemia, and diabetes mellitus in Japanese subjects. ${ }^{135}$ They observed that the Gln27Glu heterozygotes were twice as common in obese subjects, and that the frequency of the Glu27 allele was also higher in patients with type 2 diabetes mellitus than in nondiabetic subjects. ${ }^{135}$ Another Japanese study reported that the Gln27Glu $\beta_{2} \mathrm{AR}$ receptor variant was associated with obesity in males. ${ }^{141}$ Ukkola $e t$ $a l .$, found that gene-to-gene interactions among the $\alpha_{2^{-}}, \beta_{2^{-}}$, and $\beta A R$ receptor genes contributed to the phenotypic variability in abdominal obesity and plasma lipid and lipoprotein in a family study in Québec. ${ }^{142}$ Though, these and other studies show an association between the Gln27Glu, however, there is considerable debate on this association, because there have been several studies that have failed to show the significant association between $\beta_{2} A R$ gene polymorphism and obesity. ${ }^{143,144}$ Hayakawa et al., reported that Gln27Glu and Arg16Gly polymorphisms of the $\beta_{2} A R$ gene are not a major contributing factor to obesity, blood pressure, serum lipid levels, uric acid, or free fatty acid levels in 210 Japanese men. ${ }^{143}$ Oberkofler et al., reported that Gln27Glu polymorphisms in the $\beta_{2} A R$ gene is not a major factor contributing to morbid obesity in Austrian women. ${ }^{145} \mathrm{Kim}$ et al., found that the Glu27Glu and Arg16Gly polymorphisms of the $\beta_{2} A R$ gene are not major factor contributing towards obesity in Korean subjects. ${ }^{146}$ In a study on 976 Taiwanese subject Glu27 $\beta_{2} \mathrm{AR}$ allele contributes to the risk of obesity and predict obesity-related metabolic traits such as BMI, triglyceride and systolic PB. ${ }^{147}$ Furthermore, a few studies report gender-specific association between $\beta_{2} \mathrm{AR}$ polymorphism and obesity. Although the reasons for this discrepancy among studies are unclear, they may be due to the difference in the degree of obesity among study subjects or 
Table 1. $\beta_{2} A R$ gene polymorphisms.

\begin{tabular}{|c|c|c|c|c|c|c|}
\hline $\begin{array}{l}\text { Genetic data } \\
\text { SNP }\end{array}$ & AA position & $\begin{array}{l}\text { Published a } \\
\text { Common } \rightarrow \text { rare allele }\end{array}$ & $\begin{array}{l}\text { le frequencie } \\
\text { Caucasians }\end{array}$ & $\begin{array}{l}\text { the rare allele } \\
\text { African-Americans }\end{array}$ & Asians & Latino-Hispanic \\
\hline $\mathrm{T}-3459 \mathrm{C}$ & 5’ Up stream & & 0.42 & 0.16 & NR & NR \\
\hline A-3308C & 5'Up stream & & 0.001 & 0.03 & NR & NR \\
\hline $\mathrm{T}-3291 \mathrm{C}$ & 5' Up stream & & 0.44 & 0.45 & NR & NR \\
\hline A-3287T & 5' Up stream & & 0.44 & 0.45 & NR & NR \\
\hline $\mathrm{C}-3264 \mathrm{~T}$ & 5' Up stream & & 0.001 & 0.004 & NR & NR \\
\hline $\mathrm{C}-3251 \mathrm{~A}$ & 5'Up stream & & 0.44 & 0.44 & NR & NR \\
\hline $\mathrm{T}-3207 \mathrm{C}$ & 5' Up stream & & 0.008 & 0 & NR & NR \\
\hline $\mathrm{T}-3159 \mathrm{C}$ & 5'Up stream & & 0.14 & 0.19 & NR & NR \\
\hline $\mathrm{C}-2633 \mathrm{~T}$ & 5'Up stream & & 0.44 & 0.43 & 0.11 & 0.05 \\
\hline G-2547T & 5' Up stream & & 0.002 & 0 & NR & NR \\
\hline $\mathrm{T}-2387 \mathrm{C}$ & 5'Up stream & & 0.45 & 0.45 & NR & NR \\
\hline $\mathrm{T}-2274 \mathrm{C}$ & 5' Up stream & & 0.44 & 0.45 & NR & NR \\
\hline $\mathrm{C}-2265 \mathrm{G}$ & 5' Up stream & & 0 & 0.002 & NR & NR \\
\hline$-2239 \mathrm{D} / \mathrm{I}$ & 5' Up stream & Poly-A & NR & NR & NR & NR \\
\hline$-2051 \mathrm{D} / \mathrm{I}$ & 5' Up stream & & 0 & 0.05 & NR & NR \\
\hline $\mathrm{A}-1818 \mathrm{~T}$ & 5' Up stream & & 0.38 & 0.24 & NR & NR \\
\hline $\mathrm{G}-1786 \mathrm{C}$ & 5' Up stream & & 0.001 & 0.002 & NR & NR \\
\hline $\mathrm{C}-1738 \mathrm{~T}$ & 5' Up stream & & 0.004 & 0.002 & NR & NR \\
\hline $\mathrm{G}-1653 \mathrm{~A}$ & 5' Up stream & & 0.001 & 0.007 & NR & NR \\
\hline $\mathrm{C}-1531 \mathrm{~T}$ & 5'Up stream & & 0.17 & 0.32 & NR & NR \\
\hline $\mathrm{T}-1429 \mathrm{~A}$ & 5' Up stream & & 0.18 & 0.32 & NR & NR \\
\hline $\mathrm{G}-1343 \mathrm{~A}$ & 5' Up stream & & 0.44 & 0.45 & NR & NR \\
\hline $\mathrm{G}-1023 \mathrm{~A}$ & 5' Up stream & & 0.44 & 0.45 & 0.12 & 0.10 \\
\hline $\mathrm{G}-895 \mathrm{~A}$ & -31 & Met $\rightarrow$ Ile & 0.005 & 0 & NR & NR \\
\hline $\mathrm{C}-709 \mathrm{~A}$ & -93 & $\mathrm{Val} \rightarrow \mathrm{Val}$ & NF & $\mathrm{NF}$ & 0.10 & 0.27 \\
\hline G-654A & -112 & $\mathrm{Glu} \rightarrow$ Lys & 0.39 & 0.23 & NR & NR \\
\hline $\mathrm{C}-468 \mathrm{G}$ & -174 & His $\rightarrow$ Asp & 0.44 & 0.19 & 0.45 & 0.40 \\
\hline $\mathrm{C}-406 \mathrm{~T}$ & -194 & Pro $\rightarrow$ Pro & 0.001 & 0.06 & 0.29 & NR \\
\hline$-376 \mathrm{D} / \mathrm{I}$ & & 25-base D/I & 0 & 0.02 & NR & NR \\
\hline $\mathrm{T}-367 \mathrm{C}$ & -207 & Pro $\rightarrow$ Pro & 0.44 & 0.16 & 0.30 & 0.13 \\
\hline$-\mathrm{T} 262 \mathrm{C}$ & -242 & $\mathrm{Glu} \rightarrow \mathrm{Glu}$ & 0.003 & 0.05 & NR & NR \\
\hline $\mathrm{T}-47 \mathrm{C}$ & -19 BUP & Cys $\rightarrow$ Arg & 0.44 & 0.19 & NR & NR \\
\hline $\mathrm{T}-20 \mathrm{C}$ & -5 & $\mathrm{Tyr} \rightarrow \mathrm{Tyr}$ & 0.44 & 0.19 & NR & NR \\
\hline G46A & 16 & Gly $\rightarrow$ Arg & 0.38 & 0.48 & NR & NR \\
\hline C66T & 22 & His $\rightarrow$ His & 0.004 & 0.007 & NR & NR \\
\hline C79G & 27 & $\mathrm{Gln} \rightarrow \mathrm{Glu}$ & 0.44 & 0.19 & NR & NR \\
\hline G252A & 84 & $\mathrm{Leu} \rightarrow \mathrm{Leu}$ & 0.17 & 0.32 & NR & NR \\
\hline C491A & 164 & Thr $\rightarrow$ Ile & 0.02 & 0.004 & 0.01 & 0.03 \\
\hline C523A & 175 & $\operatorname{Arg} \rightarrow \operatorname{Arg}$ & 0.15 & 0.32 & NR & NR \\
\hline C659G & 220 & Ser $\rightarrow$ Cys & 0 & 0.03 & NR & NR \\
\hline G1053C & 351 & Gly $\rightarrow$ Gly & 0.26 & 0.35 & NR & NR \\
\hline T1098C & 366 & $\mathrm{Tyr} \rightarrow \mathrm{Tyr}$ & 0.004 & 0 & NR & NR \\
\hline G1239A & 413 & Leu $\rightarrow$ Leu & 0.32 & 0.44 & NR & NR \\
\hline $1269 \mathrm{D} / \mathrm{I}$ & & Poly-C & 0.36 & 0.23 & 0.41 & 0.1 \\
\hline $\mathrm{C} 1275 \mathrm{~A}$ & 3 UTR & & 0.29 & 0.54 & NR & NR \\
\hline C1277A & 3 UTR & & 0.003 & 0.03 & NR & NR \\
\hline $\mathrm{Cl278A}$ & 3 UTR & & 0.005 & 0.05 & NR & NR \\
\hline $\mathrm{C} 1629 \mathrm{~T}$ & 3 UTR & & 0.01 & 0 & NR & NR \\
\hline G1678A & 3 UTR & & 0.003 & 0 & NR & NR \\
\hline
\end{tabular}

Position of single nucleotide polymorphism (SNP) relative to ATG start codon for ADR 22 gene (NCBI Single Nucleotide Polymorphism database is online at: http://www.ncbi.nlm.nih.gov/SNP/). AA, amino acid; A, adenine; C, cytosine; G, guanine; T, thymine; D/I= insertion/deletion; NR, not reported; BUP, upstream peptide, also known as 5 leader cistron. Modified from Taylor and Bristow, $2004{ }^{151}$ and Hawkins et al., $2006{ }^{26}$ 
may be due to genetic variations between ethnic groups. However, further studies in larger populations are required to verify these results. Our findings provide strong evidence on the influence of the Gln27Glu genetic variants on lipid phenotypes, insulin and leptin levels in overweight/obese Saudi subjects.

The mechanism by which the $\beta_{2} \mathrm{AR}$ Glu27 variant is associated with a larger incidence of dyslipidemia is presently unknown. The increased resistant to agonist-induced downregulation and degradation observed in $\beta_{2} \mathrm{AR}$ Glu27 variant in vitro experiments might contribute, in part, to an increase in plasma triglyceride levels. ${ }^{35,124}$ Moreover, Glu27 allele is in linkage disequilibrium with a mutation in the promoter region, resulting in an increased synthesis of the protein with ensuing increase in lipolysis in adipocytes. ${ }^{124}$ However, these mechanisms are all contradicted by the fact that stimulation of the $\beta_{2} \mathrm{AR}$ results in no change or a decrease in plasma triglyceride level, ${ }^{148}$ and a low $\beta_{2}$ AR sensitivity is linked to hypertriglyceridaemia. ${ }^{114}$ Regarding the reasons why $\beta$-blocker treatment is associated with an increased incidence of dyslipidemia in patients with the $\beta_{2} \mathrm{AR}$ Glu27 variant, it can be hypothesized that the $\beta_{1} \mathrm{AR} \quad \beta$-blockade induced by atenolol or metoprolol, two rather selective $\beta_{1}$ antagonists, ${ }^{149}$ may result in the preferential activation of $\beta_{2}$ ARs. The consequence of this phenomenon would be even larger in patients with the $\beta_{2} \mathrm{AR}$ genetic variant resulting in dyslipidemia. The relevance of this finding includes the possibility to predict those patients that are highly likely to develop this side effect and consequently to extend to the majority of the patients the benefits of chronic $\beta$-blockade.

Therefore, despite the large number of previous studies report the influence of the Arg16Gly and GIn27Glu $\beta_{2} \mathrm{AR}$ variants on the risks of obesity, hypertension and type 2 diabetes, how these polymorphisms contribute to the development of these pathological condition remains unclear. Further large-scale analysis with well characterized traits will be necessary to elucidate the full effect of $\beta 2 A R$ variants on metabolic disturbance.

\section{Conclusions}

The exact molecular mechanism of the effects of polymorphisms on cardiovascular phenotype and outcome include unique interaction between genotypes in conformation and downstream signaling of $\beta_{2} \mathrm{AR}$. Although the association studies relating polymorphisms to CVD often result in controversial findings, it is now evident that they have an important impact. It has been suggested that the use of relaxed selection criteria may increase back- ground noise and mask possible genotype-phenotype relationships. ${ }^{150}$ For this reason, restrictive inclusion criteria, such as those requiring similar race, age, body dimension, duration, and severity of hypertension, as well as no previous pharmacologic treatment, are required for the identification of those patients in which the impact of $\beta_{2} \mathrm{AR}$ variants will have the most impact. The evidence gathered in so far are promising for the tailoring of individualized therapy for CVD patients.

\section{References}

1. Gratze G, Fortin J, Labugger R, et al. B-2 adrenergic receptor variants affect resting blood pressure and agonist-induced vasodilation in young adult caucasians. Hypertension 1999;33:1425-30.

2. Lenzen MJ, Rosengren A, Scholte op Reimer WJ, et al. Management of patients with heart failure in clinical practice: differences between men and women. Heart 2008;94:e10.

3. Eisenach JH, Barnes SA, Pike TL, et al. Arg16/gly $\beta 2$-adrenergic receptor polymorphism alters the cardiac output response to isometric exercise. J Appl Physiol (1985) 2005;99:1776-81.

4. Goldberg RJ, Ciampa J, Lessard D, et al. Long-term survival after heart failure: A contemporary population-based perspective. Arch Intern Med 2007;167:490-6.

5. Levy WC, Mozaffarian D, Linker DT, et al. The seattle heart failure model: prediction of survival in heart failure. Circulation 2006;113:1424-33.

6. Kim KM, Murray MD, Tu W, et al. Pharmacogenetics and healthcare outcomes in patients with chronic heart failure. Eur J Clin Pharmacol 2012;68:148391.

7. Lee DS, Austin PC, Rouleau JL, et al.Predicting mortality among patients hospitalized for heart failure: derivation and validation of a clinical model. JAMA 2003;290:2581-7.

8. Majahalme SK, Baruch L, Aknay N, et al. Comparison of treatment benefit and outcome in women versus men with chronic heart failure (from the valsartan heart failure trial). Am J Cardiol 2005;95:529-32.

9. Ortega VE, Meyers DA. Pharmacogenetics: implications of race and ethnicity on defining genetic profiles for personalized medicine. J Allergy Clin Immunol 2014;133:16-26.

10. Brodde OE, Michel MC. Adrenergic and muscarinic receptors in the human heart. Pharmacol Rev 1999;51:651-90.

11. Kotanko P, Binder A, Tasker J, et al. Essential hypertension in african caribbeans associates with a variant of the B2-adrenoceptor. 1997;30:773-6.

Hypertension

12. Eisenach JH, Barnes SA, Pike TL, et al. Arg16/gly $\beta 2$-adrenergic receptor polymorphism alters the cardiac output response to isometric exercise. J Appl Physiol 2005;99:1776-81.

13. Green SA, Turki J, Hall IP, Liggett SB. Implications of genetic variability of human $\beta$ 2-adrenergic receptor structure. Pulm Pharmacol 1995;8:1-10.

14. Iaccarino G, Trimarco V, Lanni F, et al. Bblockade and increased dyslipidemia in patients bearing glu27 variant of $\beta 2$ adrenergic receptor gene. Pharmacogenomics J 2005;5:292-7.

15. Brodde OE, Leineweber K. Autonomic receptor systems in the failing and aging human heart: similarities and differences. Eur J Pharmacol 2004;500:167-76.

16. Rockman HA, Koch WJ, Lefkowitz RJ. Seven-transmembrane-spanning receptors and heart function. Nature 2002;415:206-12.

17. Taylor MR. Pharmacogenetics of the human $\beta$-adrenergic receptors. Pharmacogenomics J 2007;7:29-37.

18. Bylund DB, Eikenberg DC, Hieble JP, et al. International union of pharmacology nomenclature of adrenoceptors. Pharmacol Rev 1994;46:121-36.

19. Lohse MJ, Engelhardt S, Eschenhagen T. What is the role of $\beta$-adrenergic signaling in heart failure? Circ Res 2003;93:896-906.

20. Eschenhagen T. B-adrenergic signaling in heart failure-adapt or die. Nat Med 2008;14:485-7.

21. Pitcher JA, Hall RA, Daaka Y, et al. The g protein-coupled receptor kinase 2 is a microtubule-associated protein kinase that phosphorylates tubulin. J Biol Chem 1998;273:12316-24.

22. Lefkowitz RJ. G protein-coupled receptors. III. New roles for receptor kinases and $\beta$ arrestins in receptor signaling and desensitization. J Biol Chem 1998;273:18677-80.

23. Kohout TA, Lefkowitz RJ. Regulation of g protein-coupled receptor kinases and arrestins during receptor desensitization. Mol Pharmacol 2003;63:9-18.

24. Hawkins GA, Tantisira K, Meyers DA, et al. Sequence, haplotype, and association analysis of adr $\beta 2$ in a multiethnic asthma case-control study. Am J Respir Crit Care Med 2006;174:1101-9.

25. Scott MG, Swan C, Wheatley AP, Hall IP. Identification of novel polymorphisms within the promoter region of the human B2 adrenergic receptor gene. $\mathrm{Br} \mathrm{J}$ Pharmacol 1999;126:841-4.

26. Parola AL, Kobilka BK. The peptide product of a 5 leader cistron in the $\beta 2$ adrenergic receptor mrna inhibits receptor synthesis. 
J Biol Chem 1994;269:4497-505.

27. Weir TD, Mallek N, Sandford AJ, et al. B2adrenergic receptor haplotypes in mild, moderate and fatal/near fatal asthma. Am J Respir Crit Care Med 1998;158:787-91.

28. Brodde OE, Leineweber K. B2-adrenoceptor gene polymorphisms. Pharmacogenet Genomics 2005;15:267-75.

29. Drysdale CM, McGraw DW, Stack CB, et al. Complex promoter and coding region $\beta 2$ adrenergic receptor haplotypes alter receptor expression and predict in vivo responsiveness. Proc Natl Acad Sci U S A 2000;97:10483-8.

30. Chung LP, Waterer G, Thompson PJ. Pharmacogenetics of $\beta 2$ adrenergic receptor gene polymorphisms, long-acting $\beta$ agonists and asthma. Clin Exp Allergy 2011;41:312-26.

31. Leineweber K, Buscher R, Bruck H, Brodde OE. B-adrenoceptor polymorphisms. Naunyn Schmiedebergs Arch Pharmacol 2004;369:1-22.

32. Brodde OE. B-1 and $\beta-2$ adrenoceptor polymorphisms: Functional importance, impact on cardiovascular diseases and drug responses. Pharmacol Ther 2008;117:1-29.

33. Leineweber K, Brodde OE. B2-adrenoceptor polymorphisms: Relation between in vitro and in vivo phenotypes. Life Sci. 2004;74:2803-14.

34. McGraw DW, Forbes SL, Kramer LA, Liggett SB. Polymorphisms of the 5 ' leader cistron of the human $\beta 2$-adrenergic receptor regulate receptor expression. J Clin Invest 1998;102:1927-32.

35. Green SA, Turki J, Innis M, Liggett SB. Amino-terminal polymorphisms of the human $\beta$ 2-adrenergic receptor impart distinct agonist-promoted regulatory properties. Biochemistry 1994;33:9414-9.

36. Green SA, Turki J, Bejarano P, et al. Influence of $\beta 2$-adrenergic receptor genotypes on signal transduction in human airway smooth muscle cells. Am J Respir Cell Mol Biol 1995;13:25-33.

37. Liggett SB. Molecular and genetic basis of $\beta 2$-adrenergic receptor function. J Allergy Clin Immunol 1999;104:S42-46.

38. Moore PE, Laporte JD, Abraham JH, et al. Polymorphism of the $\beta(2)$-adrenergic receptor gene and desensitization in human airway smooth muscle. Am J Respir Crit Care Med 2000;162:2117-24.

39. Koryakina Y, Jones SM, Cornett LE, et al. Effects of the $\beta$-agonist, isoprenaline, on the down-regulation, functional responsiveness and trafficking of $\beta 2$-adrenergic receptors with n-terminal polymorphisms. Cell Biol Int 2012;36:1171-83.

40. Iaccarino G, Lanni F, Cipolletta E, et al. The glu27 allele of the $\beta 2$ adrenergic receptor increases the risk of cardiac hypertrophy in hypertension. $\mathrm{J}$ Hypertens 2004;22:2117-22.

41. Iaccarino G, Izzo R, Trimarco V, et al. B2adrenergic receptor polymorphisms and treatment-induced regression of left ventricular hypertrophy in hypertension. Clin Pharmacol Ther 2006;80:633-45.

42. Reihsaus E, Innis M, MacIntyre N, Liggett SB. Mutations in the gene encoding for the $\beta 2$-adrenergic receptor in normal and asthmatic subjects. Am J Respir Cell Mol Biol 1993;8:334-9.

43. Panebra A, Schwarb MR, Swift SM, et al. Variable-length poly-c tract polymorphisms of the $\beta 2$-adrenergic receptor 3 '-utr alter expression and agonist regulation. Am $\mathrm{J}$ Physiol Lung Cell Mol Physiol 2008;294:L190-5.

44. Green SA, Rathz DA, Schuster AJ, Liggett SB. The ile164 $\beta(2)$-adrenoceptor polymorphism alters salmeterol exosite binding and conventional agonist coupling to g(s). Eur J Pharmacol 2001;421:141-7.

45. Snyder EM, Beck KC, Dietz NM, et al. Arg16gly polymorphism of the $\beta 2$-adrenergic receptor is associated with differences in cardiovascular function at rest and during exercise in humans. $\mathrm{J}$ Physiol 2006;571:121-30.

46. Rokamp KZ, Staalsoe JM, Gartmann M, et al. G16r single nucleotide polymorphism but not haplotypes of the $\beta(2)$-adrenergic receptor gene alters cardiac output in humans. Clin Sci (Lond) 2013;125:191-8.

47. Hoit BD, Suresh DP, Craft L, et al. B2adrenergic receptor polymorphisms at amino acid 16 differentially influence agonist-stimulated blood pressure and peripheral blood flow in normal individuals. Am Heart J 2000;139:537-42.

48. Dishy V, Sofowora GG, Xie HG, et al. The effect of common polymorphisms of the $\beta 2$-adrenergic receptor on agonist-mediated vascular desensitization. N Engl J Med 2001;345:1030-5.

49. Bruck H, Leineweber K, Buscher R, et al. The gln27glu $\beta 2$-adrenoceptor polymorphism slows the onset of desensitization of cardiac functional responses in vivo. Pharmacogenetics 2003;13:59-66.

50. Garovic VD, Joyner MJ, Dietz NM, et al. B(2)-adrenergic receptor polymorphism and nitric oxide-dependent forearm blood flow responses to isoproterenol in humans. J Physiol 2003;546:583-9.

51. Bruck H, Leineweber K, Beilfuss A, et al. Genotype-dependent time course of lymphocyte $\beta 2$-adrenergic receptor down-regulation. Clin Pharmacol Ther 2003;74:25563.

52. Turki J, Lorenz JN, Green SA, et al. Myocardial signaling defects and impaired cardiac function of a human $\beta$ 2-adrenergic receptor polymorphism expressed in transgenic mice. Proc Natl Acad Sci U S A 1996;93:10483-8.

53. Bruck H, Ulrich A, Gerlach S, et al. Effects of atropine on human cardiac $\beta$ 1- and/or $\beta$ 2-adrenoceptor stimulation. Naunyn Schmiedebergs Arch Pharmacol 2003;367:572-7.

54. Dishy V, Landau R, Sofowora GG, et al. B2adrenoceptor thr164ile polymorphism is associated with markedly decreased vasodilator and increased vasoconstrictor sensitivity in vivo. Pharmacogenetics 2004;14:517-22.

55. Piscione F, Iaccarino G, Galasso G, et al. Effects of ile164 polymorphism of $\beta 2$ adrenergic receptor gene on coronary artery disease. J Am Coll Cardiol. 2008;52:1381-8.

56. Barbato E, Penicka M, Delrue L, et al. Thr164ile polymorphism of $\beta 2$-adrenergic receptor negatively modulates cardiac contractility: Implications for prognosis in patients with idiopathic dilated cardiomyopathy. Heart 2007;93:856-61.

57. Bruck H, Leineweber K, Ulrich A, et al. Thr164ile polymorphism of the human $\beta 2$ adrenoceptor exhibits blunted desensitization of cardiac functional responses in vivo. Am J Physiol Heart Circ Physiol 2003;285:H2034-8.

58. Bengtsson K, Orho-Melander M, Melander 0 , et al. B(2)-adrenergic receptor gene variation and hypertension in subjects with type 2 diabetes. Hypertension 2001;37:1303-8.

59. Tomaszewski M, Brain NJ, Charchar FJ, et al. Essential hypertension and $\beta 2$-adrenergic receptor gene: Linkage and association analysis. Hypertension 2002;40:286-91.

60. Kato N, Sugiyama T, Morita H, et al. Association analysis of $\beta(2)$-adrenergic receptor polymorphisms with hypertension in japanese. Hypertension 2001;37:286-92.

61. Xie HG, Stein CM, Kim RB, et al. Human $\beta 2$-adrenergic receptor polymorphisms: No association with essential hypertension in black or white americans. Clin Pharmacol Ther 2000;67:670-5.

62. Bray MS, Krushkal J, Li L, et al. Positional genomic analysis identifies the $\beta(2)$ adrenergic receptor gene as a susceptibility locus for human hypertension. Circulation 2000;101:2877-82.

63. Tang Z, Li X, Liao D. Associations of polymorphisms in the $\beta 2$-adrenergic receptor gene with essential hypertension in han chinese population. Mol Biol Rep 2012;39:9339-45.

64. Kumar R, Kohli S, Mishra A, et al. Interactions between the genes of vasodilatation pathways influence blood pressure and nitric oxide level in hypertension. Am J Hypertens 2014. [In press] 
65. Best PJ, Holmes DR Jr. Chronic kidney disease as a cardiovascular risk factor. Am Heart J 2003;145:383-6.

66. Nickolas TL, Frisch GD, Opotowsky AR, et al. Awareness of kidney disease in the us population: Findings from the national health and nutrition examination survey (nhanes) 1999 to 2000. Am J Kidney Dis 2004;44:185-97.

67. Litovkina 0, Nekipelova E, Dvornyk V, et al. Genes involved in the regulation of vascular homeostasis determine renal survival rate in patients with chronic glomerulonephritis. Gene 2014;546:112-6.

68. Trimarco B, Wikstrand J. Regression of cardiovascular structural changes by antihypertensive treatment. Functional consequences and time course of reversal as judged from clinical studies. Hypertension 1984;6:III150-7.

69. Wadworth AN, Murdoch D, Brogden RN. Atenolol. A reappraisal of its pharmacological properties and therapeutic use in cardiovascular disorders. Drugs 1991;42:468510.

70. Hoffmann C, Leitz MR, Oberdorf-Maass S, et al. Comparative pharmacology of human $\beta$-adrenergic receptor subtypes--characterization of stably transfected receptors in cho cells. Naunyn Schmiedebergs Arch Pharmacol. 2004;369:151-9.

71. Bohm M, Grabel C, Flesch M, et al. Treatment in hypertensive cardiac hypertrophy, ii. Postreceptor events. Hypertension 1995;25:962-70.

72. Bono M, Cases A, Calls J, et al. Effect of antihypertensive treatment on the increased $\beta$ 2-adrenoceptor density in patients with essential hypertension. Am J Hypertens 1995;8:487-93.

73. Sakata K, Shirotani M, Yoshida H, Kurata C. Comparison of effects of enalapril and nitrendipine on cardiac sympathetic nervous system in essential hypertension. J Am Coll Cardiol 1998;32:438-43.

74. Trimarco B, Ricciardelli B, De Luca N, et al. Participation of endogenous catecholamines in the regulation of left ventricular mass in progeny of hypertensive parents. Circulation 1985;72:38-46.

75. Pereira AC, Floriano MS, Mota GF, et al. B2 adrenoceptor functional gene variants, obesity, and blood pressure level interactions in the general population. Hypertension 2003;42:685-92.

76. Zak I, Sarecka-Hujar B, Krauze J. Cigarette smoking, carrier state of a or $g$ allele of $46 \mathrm{a}>\mathrm{g}$ and $79 \mathrm{c}>\mathrm{g}$ polymorphisms of $\beta 2$-adrenergic receptor gene, and the risk of coronary artery disease. Kardiol Pol 2008;66:380-6; discussion 387.

77. Sethi AA, Tybjaerg-Hansen A, Jensen GB, Nordestgaard BG. 164ile allele in the $\beta 2$ adrenergic receptor gene is associated with risk of elevated blood pressure in women. The copenhagen city heart study. Pharmacogenet Genomics 2005;15:633-45.

78. Lefkowitz RJ, Rockman HA, Koch WJ. Catecholamines, cardiac $\beta$-adrenergic receptors, and heart failure. Circulation 2000;101:1634-7.

79. Feldman DS, Carnes CA, Abraham WT, Bristow MR. Mechanisms of disease: Badrenergic receptors--alterations in signal transduction and pharmacogenomics in heart failure. Nat Clin Pract Cardiovasc Med 2005;2:475-83.

80. Yamada Y, Izawa H, Ichihara S, et al. Prediction of the risk of myocardial infarction from polymorphisms in candidate genes. N Engl J Med 2002;347:1916-23.

81. Heckbert SR, Hindorff LA, Edwards KL, et al. B2-adrenergic receptor polymorphisms and risk of incident cardiovascular events in the elderly. Circulation 2003;107:2021-4.

82. Zee RY, Cook NR, Cheng S, et al. Polymorphism in the $\beta 2$-adrenergic receptor and lipoprotein lipase genes as risk determinants for idiopathic venous thromboembolism: A multilocus, populationbased, prospective genetic analysis. Circulation 2006;113:2193-200.

83. Barbato E, Piscione F, Bartunek J, et al. Role of $\beta 2$ adrenergic receptors in human atherosclerotic coronary arteries. Circulation 2005;111:288-94.

84. Abu-Amero KK, Al-Boudari OM, Mohamed GH, Dzimiri N. The glu27 genotypes of the $\beta 2$-adrenergic receptor are predictors for severe coronary artery disease. BMC Med Genet 2006;7:31.

85. McLean RC, Hirsch GA, Becker LC, et al. Polymorphisms of the $\beta$ adrenergic receptor predict left ventricular remodeling following acute myocardial infarction. Cardiovasc Drugs Ther 25:251-8.

86. Yasue $H$, Nakagawa $H$, Itoh $T$, et al. Coronary artery spasm--clinical features, diagnosis, pathogenesis, and treatment. J Cardiol 2008;51:2-17.

87. Lanza GA, Careri G, Crea F. Mechanisms of coronary artery spasm. Circulation 2011;124:1774-82.

88. Park JS, Zhang SY, Jo SH, et al. Common adrenergic receptor polymorphisms as novel risk factors for vasospastic angina. Am Heart J 2006;151:864-9.

89. Zhou X, Xiang DC, Zeng J, et al. Lack of association between genetic polymorphisms affecting autonomic activity and coronary artery spasm. Biomed Environ Sci 2013;26:689-92.

90. Pacanowski MA, Gong Y, Cooper-Dehoff $\mathrm{RM}$, et al. B-adrenergic receptor gene polymorphisms and $\beta$-blocker treatment outcomes in hypertension. Clin Pharmacol Ther 2008;84:715-21.

91. Kaye DM, Smirk B, Williams C, et al. B- adrenoceptor genotype influences the response to carvedilol in patients with congestive heart failure. Pharmacogenetics 2003;13:379-82.

92. de Groote P, Helbecque N, Lamblin N, et al. Association between $\beta-1$ and $\beta-2$ adrenergic receptor gene polymorphisms and the response to $\beta$-blockade in patients with stable congestive heart failure. Pharmacogenet Genomics 2005;15:137-42.

93. Shin J, Lobmeyer MT, Gong Y, et al. Relation of $\beta$ (2)-adrenoceptor haplotype to risk of death and heart transplantation in patients with heart failure. Am J Cardiol 2007;99:250-5.

94. Lanfear DE, Jones PG, Marsh S, et al. B2adrenergic receptor genotype and survival among patients receiving $\beta$-blocker therapy after an acute coronary syndrome. JAMA 2005;294:1526-33.

95. Troncoso R, Moraga F, Chiong M, et al. Gln(27)-->gluß(2)-adrenergic receptor polymorphism in heart failure patients: differential clinical and oxidative response to carvedilol. Basic Clin Pharmacol Toxicol 2009;104:374-8.

96. Sehnert AJ, Daniels SE, Elashoff M, et al. Lack of association between adrenergic receptor genotypes and survival in heart failure patients treated with carvedilol or metoprolol. J Am Coll Cardiol 2008;52:64451.

97. de Groote P, Lamblin N, Helbecque N, et al. The impact of $\beta$-adrenoreceptor gene polymorphisms on survival in patients with congestive heart failure. Eur J Heart Fail 2005;7:966-73.

98. Petersen M, Andersen JT, Hjelvang BR, et al. Association of $\beta$-adrenergic receptor polymorphisms and mortality in carvediloltreated chronic heart-failure patients. $\mathrm{Br} \mathrm{J}$ Clin Pharmacol 71:556-65.

99. Wagoner LE, Craft LL, Singh B, et al. Polymorphisms of the $\beta(2)$-adrenergic receptor determine exercise capacity in patients with heart failure. Circ Res 2000;86:834-40.

100.Leineweber $\mathrm{K}$, Tenderich $\mathrm{G}$, Wolf $\mathrm{C}$, et al. Is there a role of the thr164ile- $\beta(2)$-adrenoceptor polymorphism for the outcome of chronic heart failure? Basic Res Cardiol 2006;101:479-84.

101.Pezzali N, Curnis A, Specchia C, et al. Adrenergic receptor gene polymorphism and left ventricular reverse remodelling after cardiac resynchronization therapy: preliminary results. Europace 2013;15:1475-81.

102.Sotoodehnia N, Siscovick DS, Vatta M, et al. B2-adrenergic receptor genetic variants and risk of sudden cardiac death. Circulation 2006;113:1842-8.

103.Schutzer WE, Mader SL. Age-related changes in vascular adrenergic signaling: 
Clinical and mechanistic implications. Ageing Res Rev 2003;2:169-90.

104.Vu TH, Stamler J, Liu K, et al. Prospective relationship of low cardiovascular risk factor profile at younger ages to anklebrachial index: 39-year follow-up--the chicago healthy aging study. J Am Heart Assoc 2012;1:e001545.

105.Tshamba HM, a Kaut CM, Kyalubile NM, et al. Cost of hospital care for hiv/aids infected patients in three general reference hospitals in lubumbashi, dr congo: prospective cohort study. Pan Afr Med J 2013;15:76.

106.Arribas S, Marin J, Ponte A, et al. Norepinephrine-induced relaxations in rat aorta mediated by endothelial $\beta$ adrenoceptors. Impairment by ageing and hypertension. J Pharmacol Exp Ther 1994;270:520-7.

107.Hassan A, Markus HS. Genetics and ischaemic stroke. Brain 2000;123:1784812.

108.Stanzione R, Di Angelantonio E, Evangelista A, et al. B2-adrenergic receptor gene polymorphisms and risk of ischemic stroke. Am J Hypertens 2007;20:657-62.

109.Schurks M, Kurth T, Ridker PM, et al. Association between polymorphisms in the $\beta 2$-adrenergic receptor gene with myocardial infarction and ischaemic stroke in women. Thromb Haemost 2009;101:351-8.

110.Zhao N, Liu X, Wang Y, et al. Association of inflammatory gene polymorphisms with ischemic stroke in a chinese han population. J Neuroinflammation 2012;9:162.

111.Kumar A, Prasad K, Tripathi M, et al. Association of genetic polymorphisms at $\beta$-adrenergic receptor with risk of intracerebral hemorrhagic stroke in north indian population: a case control study. Neurol India 2014;62:183-8.

112.Kumar A, Tripathi M, Srivastava MV, et al. Relationship between polymorphisms in $\beta$ -2 adrenergic receptor gene and ischemic stroke in north indian population: a hospital based case control study. BMC Res Notes 2014;7:396.

113.Lima JJ, Matsushima N, Kissoon N, et al. Modeling the metabolic effects of terbutaline in $\beta 2$-adrenergic receptor diplotypes. Clin Pharmacol Ther 2004;76:27-37.

114.Arner P, Wahrenberg H, Lonnqvist F, Angelin B. Adipocyte $\beta$-adrenoceptor sensitivity influences plasma lipid levels. Arterioscler Thromb 1993;13:967-72.

115.Masuo K, Mikami H, Ogihara T, Tuck ML. Differences in insulin and sympathetic responses to glucose ingestion due to family history of hypertension. Am J Hypertens 1996;9:739-45.

116.Straznicky NE, Lambert GW, Masuo K, et al. Blunted sympathetic neural response to oral glucose in obese subjects with the insulin-resistant metabolic syndrome. Am J Clin Nutr 2009;89:27-36.

117.Iwamoto N, Ogawa Y, Kajihara S, et al. Gln27glu $\beta 2$-adrenergic receptor variant is associated with hypertriglyceridemia and the development of fatty liver. Clin Chim Acta 2001;314:85-91.

118.Landsberg L. Diet, obesity and hypertension: An hypothesis involving insulin, the sympathetic nervous system, and adaptive thermogenesis. Q J Med 1986;61:1081-90.

119.Julius S, Valentini M, Palatini P. Overweight and hypertension: a 2-way street? Hypertension 2000;35:807-13.

120.0'Dea K, Esler M, Leonard P, et al. Noradrenaline turnover during under- and over-eating in normal weight subjects. Metabolism 1982;31:896-9.

121.Masuo K, Kawaguchi H, Mikami H, et al. Serum uric acid and plasma norepinephrine concentrations predict subsequent weight gain and blood pressure elevation. Hypertension 2003;42:474-80.

122.Masuo K, Mikami H, Ogihara T, Tuck ML. Weight gain-induced blood pressure elevation. Hypertension 2000;35:1135-40.

123.Enoksson S, Talbot M, Rife F, et al. Impaired in vivo stimulation of lipolysis in adipose tissue by selective $\beta 2$-adrenergic agonist in obese adolescent girls. Diabetes 2000;49:2149-53.

124.Large V, Hellstrom L, Reynisdottir S, et al. Human $\beta-2$ adrenoceptor gene polymorphisms are highly frequent in obesity and associate with altered adipocyte $\beta-2$ adrenoceptor function. $\mathrm{J}$ Clin Invest 1997;100:3005-13.

125.Hagstrom-Toft E, Enoksson S, Moberg E, et al. B-adrenergic regulation of lipolysis and blood flow in human skeletal muscle in vivo. Am J Physiol 1998;275:E909-16.

126.Lafontan M, Berlan M. Fat cell adrenergic receptors and the control of white and brown fat cell function. J Lipid Res 1993;34:1057-91.

127.Reynisdottir S, Wahrenberg H, Carlstrom $\mathrm{K}$, et al. Catecholamine resistance in fat cells of women with upper-body obesity due to decreased expression of $\beta 2$ adrenoceptors. Diabetologia 1994;37:42835 .

128.Masuo K, Lambert GW. Relationships of adrenoceptor polymorphisms with obesity. J Obes 2011;2011:609485.

129.Eriksson P, Dahlman I, Ryden M, et al. Relationship between $\beta-2$ adrenoceptor gene haplotypes and adipocyte lipolysis in women. Int J Obes Relat Metab Disord 2004;28:185-90.

130. Hellstrom L, Large V, Reynisdottir S, et al. The different effects of a gln27glu $\beta 2$ adrenoceptor gene polymorphism on obesity in males and in females. J Intern Med
1999;245:253-9.

131.Ishiyama-Shigemoto S, Yamada K, Yuan X, et al. Clinical characterization of polymorphisms in the sulphonylurea receptor 1 gene in japanese subjects with type 2 diabetes mellitus. Diabet Med 1998;15:826-9.

132.Kortner B, Wolf A, Wendt D, et al. Lack of association between a human $\beta-2$ adrenoceptor gene polymorphism (gln27glu) and morbid obesity. Int $\mathrm{J}$ Obes Relat Metab Disord 1999;23:1099-100.

133.Echwald SM, Sorensen TI, TybjaergHansen A, et al. Gln27glu variant of the human $\beta 2$-adrenoreceptor gene is not associated with early-onset obesity in danish men. Diabetes 1998;47:1657-8.

134.Masuo K, Katsuya T, Fu Y, et al. B2- and $\beta 3$-adrenergic receptor polymorphisms are related to the onset of weight gain and blood pressure elevation over 5 years. Circulation 2005;111:3429-34.

135.Ishiyama-Shigemoto S, Yamada K, Yuan X, et al. Association of polymorphisms in the $\beta 2$-adrenergic receptor gene with obesity, hypertriglyceridaemia, and diabetes mellitus. Diabetologia 1999;42:98-101.

136. Meirhaeghe A, Helbecque N, Cottel D, Amouyel P. B2-adrenoceptor gene polymorphism, body weight, and physical activity. Lancet 1999;353:896.

137.Ehrenborg E, Skogsberg J, Ruotolo G, et al. The $q / \mathrm{e} 27$ polymorphism in the $\beta 2$-adrenoceptor gene is associated with increased body weight and dyslipoproteinaemia involving triglyceride-rich lipoproteins. J Intern Med 2000;247:651-6.

138.Vardeny 0, Nicholas G, Andrei A, et al. B-ar polymorphisms and glycemic and lipid parameters in hypertensive individuals receiving carvedilol or metoprolol. Am J Hypertens 2012;25:920-6.

139.Daghestani MH, Warsy A, Al-Odaib AN, et al. The gln27glu polymorphism in $\beta 2$ adrenergic receptor gene is linked to hypertriglyceridemia, hyperinsulinemia and hyperleptinemia in saudis. Lipids Health Dis 2010;9:90.

140.Kunnas T, Lahtio R, Kortelainen ML, et al. Gln27glu variant of $\beta 2$-adrenoceptor gene affects male type fat accumulation in women. Lipids Health Dis 2009;8:43.

141.Mori Y, Kim-Motoyama H, Ito Y, et al. The gln27glu $\beta 2$-adrenergic receptor variant is associated with obesity due to subcutaneous fat accumulation in japanese men. Biochem Biophys Res Commun 1999;258:138-40.

142.Ukkola 0, Rankinen T, Weisnagel SJ, et al. Interactions among the $\alpha 2-, \beta 2$, and $\beta 3$ adrenergic receptor genes and obesityrelated phenotypes in the quebec family study. Metabolism 2000;49:1063-70.

143. Hayakawa T, Nagai Y, Kahara T, et al. Gln27glu and arg16gly polymorphisms of 
the $\beta 2$-adrenergic receptor gene are not associated with obesity in japanese men. Metabolism 2000;49:1215-8.

144.Evans D, Mann WA, de Heer J, et al. Variation in the gene for human peroxisome proliferator activated receptor $\gamma$ (ppary) does not play a major role in the development of morbid obesity. Int J Obes Relat Metab Disord 2000;24:647-51.

145. Oberkofler H, Esterbauer H, Hell E, et al. The gln27glu polymorphism in the $\beta 2$ adrenergic receptor gene is not associated with morbid obesity in austrian women. Int $\mathrm{J}$ Obes Relat Metab Disord 2000;24:388-90.
146.Kim SH, Kim DJ, Seo IA, et al. Significance of $\beta 2$-adrenergic receptor gene polymorphism in obesity and type 2 diabetes mellitus in korean subjects. Metabolism 2002;51:833-7.

147.Hsiao TJ, Lin E. Evaluation of the glutamine 27 glutamic acid polymorphism in the adrenoceptor $\beta 2$ surface gene on obesity and metabolic phenotypes in taiwan. J Investig Med 2014;62:310-5.

148.Petraglia A, Scarpitta M, Ansalone D, et al. Negligible metabolic effects of long-term oral treatment with a new $\beta$ 2-agonist: Broxaterol. Int $\mathrm{J}$ Clin Pharmacol Res 1990;10:299-304.
149.Abraham WT, Iyengar S. Practical considerations for switching $\beta$-blockers in heart failure patients. Rev Cardiovasc Med 2004;5:S36-44.

150.Stella P, Bigatti G, Tizzoni L, et al. Association between aldosterone synthase (cyp11b2) polymorphism and left ventricular mass in human essential hypertension. J Am Coll Cardiol. 2004;43:265-70.

151.Taylor MR, Bristow MR. The emerging pharmacogenomics of the $\beta$-adrenergic receptors. Congest Heart Fail 2004;10:2818. 